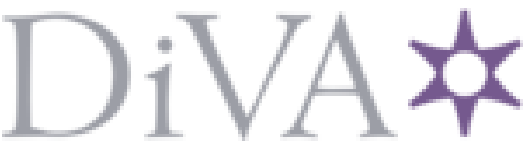

http://www.diva-portal.org

\title{
Postprint
}

This is the accepted version of a paper published in Journal of Documentation. This paper has been peer-reviewed but does not include the final publisher proof-corrections or journal pagination.

Citation for the original published paper (version of record):

Sköld, O. (2017)

Getting-to-Know: Inquiries, Sources, Methods, and the Production of Knowledge on a Videogame Wiki

Journal of Documentation, 73(6): 1299-1321

https://doi.org/10.1108/JD-11-2016-0145

Access to the published version may require subscription.

N.B. When citing this work, cite the original published paper.

Permanent link to this version:

http://urn.kb.se/resolve?urn=urn:nbn:se:uu:diva-336745 
Getting-to-know: inquiries, sources, methods, and the production of knowledge on a videogame wiki

\section{Structured Abstract:}

Purpose - The purpose of the paper is to investigate the sociocultural underpinnings of wiki-based knowledge production in the videogame domain, and to elucidate how these underpinnings relate to the formation of wikis as resources of videogame documentation.

Design/methodology/approach - The paper is based on a three-month ethnographic investigation of knowledge practices on the Dark Souls Wiki ('the DSW'). In focus of the analysis were the boundaries and knowledge aims of the DSW, together with how its contributors organized inquiries and used various sources, methods of investigation, and ways of warranting knowledge claims.

Findings - The principal result of the paper is an empirical account of how the DSW functions as a culture of knowledge production, and how the content and structure of the wiki connects to the knowledge practices of its contributors. Four major factors that influenced knowledge practices on the wiki were identified: $i$. the structures and practices established by the community's earlier wiki-efforts; ii. principles and priorities that informed wiki knowledge practices; iii. the characteristics of the videogame in focus of the site's knowledge-building work; iv. the extent and types of relevant documentation provided by videogame industry, the videogaming press included.

Originality/value - Previous research has shown interest in investigating the mechanisms by which community-created knowledge and online resources of documentation emerge, and how these are utilized in play. There is however little research seeking to elucidate the sociocultural structures and practices that determine and sustain collaborative online videogame knowledge production.

Keywords: Knowledge production, Videogames, Ethnography, Wikis, Practices, Social media

Article Classification: Research paper 


\section{Introduction}

When Ward Cunningham developed the first instantiation of wiki technology in the mid 90s, his stated aim was to create "[t]he simplest online database that could possibly work" (Cunningham and Leuf, 2002). Whereas the basic functionalities of current wiki platforms are described in largely similar terms, research has shown that wiki-based knowledge production is considerably more regulated and ritualized than the open-ended characterization of the wiki as a collaborative content management system seems to necessitate (e.g., Jemielniak, 2014; Mittell, 2009; Reagle, 2010; Sundin, 2011; Toton, 2008). The apparent discrepancy between the modularity with which the wiki platform has become synonymous, and the distinctly regimented ways in which knowledge is produced on Wikipedia and other wikis may be explained by insights attained in the sociocultural study of knowledge [1], where knowledge production is colloquially viewed as bounded and particular (Becher, 1989; Knorr-Cetina, 1999; Latour and Woolgar, 1979). The production of knowledge is here understood as the result of patterned activities connected to the aim of making "organized statements of facts or ideas" (Bell 1973, p. 41, as cited in Knorr-Cetina 1999, p. 6) in a specific and regulatory context, be it professional or leisure, university science labs, or wikis (cf. Hartel, 2010; Law and Lynch, 1988; McKenzie and Davies, 2010). Here, the overarching purposes of this paper emerges. The paper aims to delve into how wikis function as bounded cultures of knowledge production, and to seek answers to how the formation of the wiki as a documentary resource of recorded information connects to the practices of knowledge production present on the site.

The present work achieves these purposes by reporting on a three-month ethnographic examination aiming to uncover the sociocultural underpinnings of knowledge production on the Dark Souls Wiki ('the DSW'), a wiki in the area of contemporary videogame culture dedicated - during the period of study - to investigating and documenting the functionalities of the game Dark Souls II ('DS2'). Previous related studies have strongly underlined the important and "almost symbiotic" (Barr, 2014, p. 120) relationship between videogame communities and social media, and have shown interest in investigating the mechanisms by which community-created knowledge and online documentary resources emerge (e.g., Toton, 2008; Steinkuehler and Duncan, 2008; Mittell, 2013), and how these are utilized in play (e.g., Harviainen and Hamari, 2015; Harviainen and Vesa, 2016; Sköld et al., 2015). However, there is little research seeking to elucidate the structures and activities that determine and sustain collaborative online videogame knowledge production. The relevance of the present study is additionally heightened by previous research on knowledge-producing enterprises like scholarly research (Becher, 1989; Latour and Woolgar, 1979; Knorr-Cetina, 1999) and Wikipedia (Fallis, 2008; Magnus, 2009; Tollefsen, 2009), which indicate the usefulness of sociocultural analysis of knowledge production to produce insights into the orderings and operations that make up how knowledge is created and warranted in the domain of videogame-related social media. This paper thus contributes to LIS research by shedding light on the sociocultural aspects of knowledge production and creation of documentation in the large and influential videogame domain - an important step towards better understanding interactions with recorded information and knowledge in contemporary online play and videogame culture.

Three research questions guided the present study of describing and analyzing wiki-based knowledge building in the videogame domain: (1) What are the boundaries and knowledge aims that characterize the DSW as a culture of knowledge production? (2) Which day-to-day knowledge practices are carried out on the wiki, with a specific focus on how the DSW's community members come to attain knowledge by the organization of inquiries and the use of various sources, methods of investigation, and ways of warranting knowledge claims? (3) What conclusions regarding the emergence of the DSW as a community-created documentary 
resource in the videogame domain can be drawn on the basis of knowledge practices on the site? The study is theoretically inspired by LIS document studies (e.g., Brown and Duguid, 1996; Frohmann, 2004) and sociocultural analyses of knowledge production in the sciences (e.g., Becher, 1989; Knorr-Cetina, 1999).

\section{Literature review}

As videogames and videogaming have gained cultural and economic significance on an unprecedented scale in the 2000s (e.g., Hunter, 2011; Malaby, 2007; Pearce, 2009; Shaw, 2010), they have also become the object of considerable academic attention. This paper positions itself in the growing body of work focused on investigating knowledge and information in the intersection of videogames and player-authored social media resources like wikis, blogs, and discussion forums. The findings of previous research efforts can be systematized into three principal groupings, ordered by their level of abstraction.

\subsection{Social media and videogames}

Firstly, there is a large segment of studies that accentuate the highly reciprocal relationship between social media and videogames in contemporary online life. This relationship is in some cases architectural; social media services function in part as gaming platforms and a great variety of videogames have a built-in functionality to mediate users' contact requests and gameplay information via Facebook, Twitter, and other services (Barr, 2014; Warmelink, 2013). The closeness of videogames and social media is also apparent in terms of how players interact with the game and with each other (Harviainen et al., 2012). Studies of multiplayer videogames have shown social media to be an important multi-purpose material infrastructure with an associated set of practices technically located 'outside' of the game world, yet very much an integral part of gameplay practices and videogame-community emergence (e.g., Adams, 2009; Boellstorff, 2008; Hamilton et al., 2014; Harrison, 2009; Nardi, 2010; Taylor, 2006). The uses of social media by players include tasks of organization and management of player groupings, in-game resources, and knowledge creation and sharing (Chen, 2012; Golub, 2010; Vesa, 2013; Warmelink, 2013). Social media is also an outlet for the narrative- and experience-sharing practices of videogame communities (Harrison, 2009; Wirman, 2007), which are seen to be tied to mechanisms of meaningmaking and the building of identity (Albrechtslund, 2010). Social media and videogames can be understood as distinct environments, where videogame-related websites are a different or second-order manifestation of game and gameplay (e.g., Boellstorff, 2008, p. 199; see also Hamilton et al., 2014). The principal contravening viewpoint is that games and social media are parts of a complex and multi-location system of activity and play, knowledge production and culture, which transcends the discreteness of the individual platforms (Golub, 2010; Pearce, 2009).

\subsection{The study of videogames, information, and knowledge}

The second grouping of studies examine the information and knowledge processes taking place in videogames and game-related social media environments more closely. Here, Jenkins' $(2006$; 2013) notion of 'participatory cultures' frequently serves to analyze and explain the prolific creation of resources - databases, blogs, wikis, websites, fan fiction, strategy guides, mods walkthroughs - evident in many videogame communities (e.g., Hunter, 2011; Martin and Steinkuehler, 2010; Wirman, 2007). Defining characteristics of game communities in this view include a close connection between play, the production of game-related knowledge, and community participation (Wirman, 2007, see also Pearce, 2009), and the high status of collaboratively created information sources and peer-to-peer information exchange (Martin and Steinkuehler, 2010; Steinkuehler et al., 2010). How 
players seek and use information has further been researched by, among others, Adams $(2005 ; 2009)$. Adams find that players employ diverse strategies in their efforts of retrieving the information they need to succeed during gameplay and suggests that the negotiations of meaning that follow a player group's shared information-seeking activities is a factor in the formation and maintenance of player communities. Practices of information seeking, evaluation, interpretation, synthesizing, and dissemination in online videogames are found to be more collective in character than those presented in standard models of individual learning (Steinkuehler, 2007; Martin and Steinkuehler, 2010). Players' information practices and the information systemic properties of game platforms mutually shape play (Karlova and Lee, 2012; Harviainen and Hamari, 2015). Information interacts with players' capacity for gaming and enacts the exercise of power over others by being a currency in gameplay situations (Harviainen and Savolainen, 2014; Harviainen and Hamari, 2015).

\subsection{Player-authored online information resources}

The third set of studies focuses specifically on the creation, curation, and use of online player-authored information resources. Several papers here engage in a discussion of how to characterize the activities involved in the building and maintenance of such sites in relation to the notions of work and play (Barr, 2014; Bullard, 2013; Steinkuehler and Duncan, 2008). It is jointly concluded that these efforts represent both spheres: the site-building activities are goal-oriented, organized, and made possible by consistent work and specialized knowledge but are nevertheless voluntary and joyful in nature. Barr (2014, p. 119), for example, finds that videogame wiki-editors have an "academic proficiency" in terms of the contents and quality of their contributions, although their primary motivations are enjoyment and their liking of the videogame in question. Bullard (2013) employs Stebbin's (1982; 1997) concept of 'serious leisure' to investigate the blurring of work and play in the creation of playergenerated information resources in World of Warcraft ('WoW'). Also focusing on WoW, Steinkuehler and Duncan (2008, p. 530) explore the "scientific habits of mind" that underpin the collaborative knowledge production taking place both in the game and in associated sites and services. They show that the game community employs, and fosters, many modes of knowledge practices such as systems thinking and model based reasoning (Steinkuehler and Duncan, 2008, Table 1 on p. 534). Research on fandom wikis have yielded results that are of interest for this paper. A relevant line of inquiry in fandom scholarship concerns itself with the development and implementation of the policies that establish what is appropriate structure and relevant content on fan wikis. Fan wikis are important information resources that generally hold an array of knowledge modes, including original research, theory building, documentation, and more creative efforts such as fan art (Mittell, 2013). As shown by Toton (2008), these modes of knowledge are of different priority in different fan wikisthe result of a communal selection process where aspects or issues are deemed to be of varying degrees of relevance. In a study of a wiki dedicated to the Lost television series, Mittell (2009) outlines how the encyclopedic ambitions of Wikipedia and the established tropes of fan culture are major influences on how principles of selection and priority have developed on the site. Fan wikis are here approached not solely as places of reference, but rather as important sites of participatory fandom whose contents and structures to a significant extent can be read as dynamic representations of the viewpoints and priorities of the communities that create them (Bullard, 2013; Newman, 2011).

\section{Theoretical framework}

This paper employs an analytic framework informed by "documentalist" LIS research (Frohmann, 2004, p. 10) and the sociocultural study of knowledge (e.g., Knorr-Cetina, 1999). The documentalist approach implies that information and knowledge are phenomena 
irrevocably tied to the practices, technological means, and social groupings of people - and that they should be studied as such. Researchers have used documents as an analytic notion in the study of personal information management (Hartel, 2010), the definition and organization of tasks (McKenzie and Davies, 2010), and the workings of organizations (Davies, 2008). Studies have moreover shown how documents play an important role in the emergence and maintenance of social groups and shared practices (Brown and Duguid, 1996; Trace, 2007), and in the scientific production of knowledge (Frohmann, 2004; Shankar, 2009). The document perspective is useful for the purposes for this paper because it provides a way to operationalize the notions of information and knowledge in the empirical context of the DSW, which is characterized by a high degree of mediated interaction and communication (e.g., Jenkins, 2006; Steinkuehler, 2007; Wirman, 2007). Information is here conceived of as recorded information, i.e., documentation (cf. Buckland, 1991, pp. 3-6). Interactions with information in the empirical setting of the DSW are defined as the activities that produce, modify, generate, or use documentation - texts, images, comments - or documentary traces-logs and other indicators of activity (cf. Geiger and Ribes, 2011). The document perspective also works to more accurately describe and analyze the modes of communal knowledge production in focus of this paper. Following Buckland (1991, p. 3f), knowledge is defined as that which is imparted when someone is informed. In context of the DSWians venture to investigate and document DS2 and its workings, the fundamental operational mechanic by which knowledge is produced and imparted are activities of documentation: to produce, discuss, and circulate texts, images, and videos on the site.

Sociocultural studies of knowledge production provide additional conceptual tools. Here, the focus is set on the factors that determine how knowledge is produced in a certain setting rather than on the management or application of knowledge itself. These factors often include for example activities, means and materials, the social organization of the persons engaged in knowledge production, and the principles and logics of the enterprise under study (Becher, 1989; Latour and Woolgar, 1979; Knorr-Cetina, 1999). Knorr-Cetina (1999) argues that this mode of analysis is not reserved for the sciences, and is applicable to other production contexts as well. The DSW will be analyzed as a specific and singular culture where the production of knowledge is practiced, that is, bound to activities. Two principal and interrelated concepts will be applied to facilitate this analysis: knowledge practices and knowledge cultures. The term knowledge practices will be used to refer to the patterned activities that make up the production of knowledge on the DSW, carried out by the wiki's community of participants. Connecting to the practice-theoretical vocabulary of Schatzki (1996, p. 98), these practices are seen to be "integrative" in character and specialized in the domain of videogame-community knowledge production. Knowledge practices on the DSW are analyzed as socially and culturally embedded in the wiki's knowledge culture, a term which denotes the totality of "aggregate patterns and dynamics" of the DSW, including the knowledge practices and the principles and priorities that inform them included (KnorrCetina, 1999, p. 8).

A first step in answering the research questions of the present paper was to develop a set of empirical focus points on the basis of earlier inquiries into settings of knowledge production, specifically Knorr-Cetina (1999) and Becher (1989) (Table 1). The focus points were designed to direct analytical attention and data collection during the study of the DSW so as to facilitate the investigation of the paper's research questions. Table 1 holds an overview of the foci and the kinds of occurrences and phenomena they draw into view. Each focus point corresponds to a subheading in the paper's analysis section.

[Insert Table 1 here] 


\section{Materials and methods}

\subsection{Research setting}

Everyone [in the Dark Souls-community] is trying to puzzle it out [...]. Stanton (2014) [2]

Dark Souls II ('DS2') is the second game in the three-part Dark Souls franchise. DS2 was released in March 2014 and had sold 2.9 million units worldwide as of July 2015 (Purchese, 2015). The Dark Souls series is noted for its high level of difficulty. The challenges that the Dark Souls games present to the player are manifested in several core aspects of gameplay: certain items are hard to find, the games' hard-coded rules are oblique, player mistakes are punished severely, and the games' narratives are told indirectly, through allusion and rumor. Moreover, the games provide the player with little or no indication as to how such obstacles can be navigated. It is plausibly this combination of high difficulty and informationrestriction-as-game design that has led the Dark Souls games' online communities to position the DSW, and other sites with knowledge building and sharing-functions (Reddit, YouTube, other wikis), at important places in community life. The DSW is a wiki devoted to Dark Souls I, II, and III. The DSW was founded in 2011 and had at the time of DS2's release become one of the major English-language Dark Souls wikis by virtue of its users' - the DSWians - successful documentation of DS2's predecessor, DS1. The number of monthly active registered editors on the wiki varied between 250 and 300 in the course of the inquiry, 140-170 of whom participated in the writing of articles. The DSW runs on the MediaWiki platform and is hosted by Wikia, a commercial but free-to-use wiki hosting service.

The present paper is based on an ethnographic investigation of the DSW that began on the day before DS2's North American release in March 2014, and continued for three months. [3] This period marks a surge in wiki activity, which transformed the DSW from a site holding little information about DS2 to becoming a high-grade documentary resource about the game - complete with textual and visual representations of the game world as well as strategies for attaining a range of in-game goals and analyses of gameplay mechanics. Put in approximate numbers, the DSW's article count rose from 1800 to 2600 during the months following the release of DS2. Editor activity similarly increased. In comparison with the preceding three-month period, the total number of active editors doubled and the number of editors involved in article work tripled. The studied timeframe was hence a time of change, where the DSWians were simultaneously tasked with exploring and documenting of a new object (DS2) and with the need to introduce an influx of new editors to the DSW's established knowledge practices. Beneficially, this situation resulted in repeated and varied articulations of - and challenges to - the DSW's knowledge culture in the actions and articulations of the wiki contributors.

\subsection{Study design and execution}

The design of the DSW study draws on multiple currents of ethnographic writing. The fundamental scope and methodological outline was influenced by Geertz (1973, p. 5-10) and works on the application of ethnography in the study of online phenomena (e.g., Gatson, 2011; Hine, 2000; Markham, 2013). The choice of a field site follows the arguments of Marcus (1995, p. 110f), who asserts that a single-site ethnography, if "strategically situated," can provide insights about multi-site phenomena, like videogame-community knowledge production, for instance. The more specific methodology employed in data collection was of the so-called 'trace' or 'database' ethnographic variety, as developed and showcased by among others Geiger and Ribes (2011) and Schuurman (2008); see also Mittell (2009), Fallis (2008), and Hine (2000, p. 18-27). These approaches argue for the productive possibilities of using participant observation and analysis of log data to gain insights into the interactions and 
practices of users and communities taking place in technological platforms that generate rich traces of interaction - such as the DSW's MediaWiki infrastructure.

Material was collected by participant observation and by gathering data from the site. The day-to-day study of the DSW consisted of observing and taking part in the discussions and activities of the wiki's different arenas, including the article space, comment sections, forums, and chat channel. At the start of each session on the DSW I also reviewed the wiki's $\log$ of recent activities to see what had occurred since my last visit and, if something proved to be of interest to the study, I pursued it further. A research journal was kept during the entirety of the study so as to document my activities and observations. The materials collected as a result of the DSW study include change logs from the 94 days of the study, detailing almost all activity taking place on the wiki. These logs retained records from the low 200s and up to over a thousand interactions a day, averaging 584. Other materials produced are field notes and over 110 documents that were downloaded from the DSW. This material principally includes discussions from the forums or comment sections, chat logs, site policies, and interactions from the personal blogs ('walls') of the DSWians. Materials from the DSW were continuously imported into a RQDA database for purposes of overview and reference. Taking initial direction from the schemata presented in Table 1, data collection was carried out jointly with data coding and analysis. Initial codes and associated memos were created when data was imported into the materials database, and then revised as the study progressed. The theoretical insights attained by this process were used to direct and focus the further study of the DSW. The process of analysis in its entirety was inspired by the steps and approaches outlined by Charmaz (1983), Corbin and Strauss (1990), and Glaser and Strauss (1967).

This study design entails multiple limitations. Relating to its scope, several aspects of videogame knowledge culture are only touched upon briefly and should be investigated further in future inquiries, including the organization of work and the MediaWiki infrastructure. The paper's focus on knowledge practices also implies a limitation. At the center of the analysis of knowledge production on the DSW are the activities and articulations of the DSWians and the way these relate to the principal manifestations of the wiki's knowledge culture. While relevant, analyses of symbols and meaning in DSW knowledge culture are not included in this study. Further, the choice to study a multi-site phenomenon like videogame-community knowledge production (cf. Marcus, 1995; Pearce, 2009) using single-site ethnography has its merits in terms of depth and dependability, but makes the transferability of the results hard to determine.

\subsection{Ethical considerations}

The ethical stance that permeated the planning and execution of the study of the DSW rests on three principal points of consideration; the policies of Wikia; the writings of Nissenbaum (2010) on the topic of privacy; and the character of the study and of the wiki's community. During the course of the study of knowledge production on the DSW it was assumed that the site's contributors were aware that contents posted to the site became publically viewable, and that "the information [users] put on the wiki can be copied and reused by anyone", as stated by Wikia's policies (Wikia, 2017). These assumptions echo the ways in which the contents and activity logs of the DSW were used by members of the community - and the norms and values associated with such use - indicating that the stance of the present study is ethically warranted (Nissenbaum, 2010). Finally, the characteristics of the DSW community and their venture of knowledge production and documentation were not seen to by themselves actualize any ethical dilemmas with regards to their vulnerability or risks associated with the writing and publishing of this paper. Rather, it is hoped that the present study may empower the DSWians and other knowledge-making communities in the domains 
of videogames or digital culture more broadly by showing the high levels of organization and productivity, expertise, and commitment implicit in their endeavors.

\section{Results}

Well, it looks like the wiki is about to get busy again [with the release of DS2]. (Jativoke, March 2014)

\subsection{Content and nature of DSW knowledge-culture}

\subsubsection{General characteristics}

The DSW is a site of reference and analysis, where an international grouping of contributors works towards breaking down and documenting the entries in the Dark Souls series of threedimensional action roleplaying games into a wiki-based documentary resource. During the study, efforts on the DSW was led and moderated principally by the wiki's five administrators - Kamishiro, Furuken, Tomiko, Mayu, and Qing - together with a cadre of high-activity users. [4]

The DSW knowledge culture was to a significant degree defined by its knowledge aims, which in the context of everyday activities served as a key point of reference for all knowledge practices carried out on the wiki. The aims consisted of a collection of principles and ambitions outlining the short- and long-term goals of knowledge building on the DSW, as well as providing a basis for both the evaluation of work and the selection of what falls within the scope of the wiki. During the timeframe studied, the large increase in the number of new editors on the DSW prompted frequent and varied expressions of the wiki's knowledge aims so as to regulate and coordinate practices of knowledge production. The aims were articulated in site policies or, most commonly, in the form of criticisms and corrections written in response to wiki activity outside the confines of DSW praxis. These interactions defined the DSW as a knowledge culture aiming to construct a free and collaboratively created resource of documentation written in a to-the-point tone, and with a high degree of standardization regarding nomenclature and structure. Documentation provided by the DSW should be "accurate and relevant [...]" (Kamishiro, August 2014), "easily navigable [...] concise" (Jimopup, June 2014) and be clearly written so as the "average 'Human Being' [and] not [only] 'Gamer' should understand [the contents of the wiki]" (Kamishiro, March 2014).

The knowledge aims also set the external boundaries of the DSW's knowledge culture by outlining its intended function in relation to the ecosystem of sites that nowadays surround many newly-released videogames of some anticipation. The DSW was distinguished from forums and strategy guides - accentuating the centrality of knowledge production on the site and the standards and established knowledge practices that supported them - and excluded content that was not a product of the collective efforts of the DSWians, like pages serving as advertisements for YouTube content creators. Importantly, the DSW was also described as being semi-autonomous in relation to the work and findings of other DS2 wikis. "We're a wiki, not a dumping pool for information from other wikis," wrote an AWC (May 2014). [5] This sentiment was echoed by Daiki (March 2014) among others, and became codified in the DSWs Media Policy, formulated in May-June 2014 principally by Jimopup, Kamishiro, and Furuken:

To ensure the legitimacy of our wiki, we must source and write our own information; not simply be a collection of information taken from other sites. All information not quoted directly from the games should be originally written by the authors and editors of our articles. Likewise, all images which are not part of the in-game files or "official" promotion should be captured by the authors and editors (Jimopup, June 2014). 
The aim to hold only documentation that was the product of the DSW's contributors was here tied to the success of the wikis's principal goal, to produce legitimate documentation of DS2 and its workings.

\subsubsection{Organization and constitution of daily knowledge practices}

[C]ount me in sir! :D [R]eady to research when you are! (Hong, June 2014).

The rhythm of everyday work on the DSW can be described as flat and persistent, and there was always activity on the wiki. A typical day on the DSW contained knowledge practices of many kinds and complexities taking place on the wiki. These practices ranged from lowthreshold tasks - like simple Q\&A exchanges or the creation of basic documentation detailing some aspect of DS2 - to more demanding projects, such as the formatting of articles to fit the standards of structure and language use, and the application of principles of selection and priority. Table 2 contains an overview of the most common knowledge practices on the DSW. It should be noted that the knowledge practices in Table 2 should be interpreted along the axis of creation-of-content-editing-of-content. A prominent feature of DSW knowledge culture was that users could edit a significant portion of the videogame documentation present on the wiki. Thus the knowledge practices of article writing, policy work, and file management, for example, could be acts of content creation or content editing depending on the specific instance.

\section{[Insert Table 2 here]}

During the time I spent on the DSW, knowledge production was only seldomly coordinated on a site-wide level, and the efforts of the individual editor was always unregulated in terms of its focus. When attempts were made to direct the work of the DSWians, they existed in the non-mandatory form of suggested priorities. Such attempts were often put together by highactivity users or the wiki's administration team and principally served as organizational help for these groups of users alone. The common concern here was that the regular editor of the DSW would be discouraged by strongly worded directives and thus lose interest in contributing to the site. An example can be found in the attempt at organization of DSWs editors launched by chat moderator Tokugawa, about three months after the release of DS2. The initiative was motivated as follows:

These last few months, the edits on the wiki have been... Well honestly, they've mostly been a jumbled mess. I feel we need to organize what all our editors are doing, so as not to just slowly inch our way to being a proper informative source (Tokugawa, June 2014).

This sentiment was echoed by the admin Tomiko, who attributed the lack of coordinated knowledge-production efforts to the release of DS2 and the subsequent arrival of many new editors to the wiki:

The popularity of [DS1] and the subsequent release of [DS2] was both a blessing and a curse, in that it attracted a lot of new editors, but that the corresponding volume of edits have varied considerably in quality and direction (Tomiko, June 2014).

While both Tokugawa and Tomiko, along with many other high-profile DSWians like admins Furuken and Kamishiro, stood behind this initiative it was quickly established that the potential tradeoff for more widespread coordination of knowledge-building was a decline in editor commitment to the DSW, and this was deemed unacceptable. Jimopup articulated the principal critique of Tokugawa's coordinative exercise by pointing out the perceived 
incompatibility between priority systems and widely practiced ways of article work on the DSW: "[p]eople add what information they have. It doesn't make sense to tell them [what to add to the wiki]" (Jimopup, June 2014).

\subsection{Getting-to-know}

\subsubsection{Questions and inquiries}

On the DSW, investigative knowledge practices were directed by the asking of questions and the organization of inquiries. These expressions of knowledge goals were varied in terms of complexity and scope, and ranged from basic requests - for example, "How do you use it?" (Haruna, March 2014) - to the detailed exploration of gameplay mechanics.

The posing of questions and the arrangement of inquiries on the DSW during the time of study were closely tied to two factors: the practices of article work on the site, and the DS2 in-game progress made by the many DSWians who were engaged in playing the game in parallel to contributing to the wiki. Article work on the DSW was predominantly approached as an incremental process where available knowledge - albeit obviously incomplete - was documented to be revised or complemented later, when more was known. This principle, in combination with the low progress of the DSWians' DS2 playthroughs in the days following the game's release, resulted in the majority of initial contributions to the wiki comprising the creation of articles for in-game locations and items encountered by the DSWians in the early sections of the game. Editor Kawi's posting of an article detailing one of the first boss encounters on the day after DS2 began selling in North America is a typical example of such early stage knowledge practices. Kawi wrote:

"Noticed there wasn't a page [for the boss] yet. Created the page, added some basic info from what I gathered with my fight [with the boss] [...]" (Kawi, March 2014).

As the DSWians progressed through DS2 and continued editing work lessened the need for documentation of DS2's most basic aspects and functionalities, the amount of undirected knowledge-building practices prompted by encounters during gameplay began to diminish and the variety of aim-oriented inquiries grew greater. Common incentives to inquire and to ask questions included editors noticing inaccurate documentation on the wiki, or that an issue was in apparent need of further investigation. Emi wrote: "After seeing several messages stating a Pharros Contraption was 'pointless' I decided to [investigate], [and] it turns out it was actually healing me, has anyone else noticed this?" (Emi, March 2014). Incomplete documentation, for example regarding secret areas or hard-to-find items, likewise led to such findings being requested, investigated, and the results documented on the wiki. Initiatives seeking to document the basic features of the DS2 game-world also gave way to more intricate investigations and discussions regarding the precise function of items, successful strategies in encounters with enemies or bosses, and the explorations of the rules that governed how various aspects of the game functioned. Yoshiro, for example, decided to return to Dyna and Tilo - a duo of item-trading NPCs encountered early in the game - to uncover the rules governing their trading mechanic. Yoshiro wrote:

So, after playing through the game for quite some time, I returned [...] to visit [Dyna and Tilo]. I wanted to see what items they will accept and refuse, you know? (Yoshiro, March 2014).

The partial shift in focus from recording to investigation illustrated by Yoshiro's contributions is further visible in many efforts and discussions taking place on the DSW after the initial phase of article creation that followed DS2's release. Notable examples include figuring out the rules that govern progression in the in-game player factions and the functionality and gathering strategies of important consumable items. 


\subsubsection{Methods and source materials}

The DSWians consulted a range of source materials and employed a variety of approaches in their investigations of DS2 and its constituent elements. Table 3 contains an overview of methods and source materials that were a commonly observed part of the investigative DSW knowledge practices.

\section{[Insert Table 3 here]}

A well-used approach among DSWians to finding things out about DS2 was to consult the plethora of sources available online and offline. The usage of sources shifted extensively during the study of the DSW and was seemingly tied to the DS2 release timeframe to some extent. Before the release of the game, promotional material like trailers released on YouTube, videogame news coverage, and Twitch streams of players with early access to the game were commonly referenced on the DSW. After release, the findings of other communities and players regarding the workings of DS2 - often posted in forums or on YouTube - were repeatedly used in DSW-knowledge building. Another shift in the usage of sources occurred when the much anticipated official DS2 strategy guide was released and subsequently widely employed in DSW article work. The consulting of sources was often the first approach to be tried when the DSWians came upon an unknown or unclear topic, as illustrated by Tomiko in the investigation of the connection between the attunement statistic and number of available spell slots:

Do you know a good resource that lists the breakpoints for each spell? Otherwise we'll either need to look into the game files or do some very tedious testing ourselves (Tomiko, April 2014).

When the DSWians decided to conduct testing themselves, the most important and heavily used source material was DS2 itself, and the principal method of its investigation was to play and to record. Gameplay as a method of DSW knowledge building was employed in several ways during the studied timeframe and was in some cases undirected, in some cases directed. Undirected recording is often what happened when the DSWians played DS2 for fun or completion, and recorded the things they came across. Rong's post in the comment space of the article on the in-game region Huntsman's Copse provides an example of this approach:

OMG I just discovered a new area inside of [Huntsman's] Copse. To get to it jump on to the pillar where you would get the Pharros Lockstone, then [continued instructions] (Rong, March 2014).

Directed recording occurred when DSWians aimed at investigating something particular and then adapted gameplay in order to attain their goal. Daiki, for instance, worked to acquire an item set with the intent to "make [wiki] pages for each part" (Daiki, March 2014). A similar approach was used by Kamishiro, who, in a discussion about the importance of improving the DSW's location pages, wrote: "I actually plan on improving the location pages myself soon. I have taken note of items and such as I've been going along" (Kamishiro, March 2014). The method of playing-and-recording allowed the DSWians to successfully use DS2 as an immensely useful source which included basic aspects of the game world's fundamental building blocks - locations, items, NPCs, enemies, dialogue, and story. The drawback of this approach was that the insights that could be gained from playing and recording were limited by the level of detail provided in-game. Since DS2 is designed to supply the player with only bare-bone information concerning its functionalities and narrative setting, the DSWians often found that gameplay did not provide sufficient insights into the game's more complex aspects. In such cases explorative gameplay methods were employed by the DSWians. 
Notable examples of investigations that occurred during the study aimed at bettering the understanding of the rules that govern progression in the in-game player faction Brotherhood of Blood ('BoB'), the item trading-mechanic of NPC duo Dyna and Tilo, and the factors that influence the workings of the spell Crystal Magic Weapon. The study of BoB can exemplify the common structure of investigations on the DSW:

1. The DSWians attempted to identify the relevant parameters of the gameplay mechanic under study. In the case of $\mathrm{BoB}$, it was decided that the win-loss ratio of player-vs-player combat ('PvP') was an important parameter, and that the item Blood Seal Ring was not.

2. The parameters were then used to establish a repeatable scenario which allowed for the exploration of the mechanic's cause-and-effect relationships. BoB was hence investigated by DSWians engaging in PvP and keeping track of their winloss ratio while monitoring their progression in the faction.

3. DSWians then repeated the scenario and submitted the results, which were then discussed. Apropos the BoB win-loss ratio, an AWC reported that a "[n]egative kill [win] count is impossible. For example: 50 kills, 100 deaths [losses] remain 0 kills. Not -50 kills" (AWC, July 2014).

While there were variations, the main steps of DSW investigations into the functioning of DS2 were the identification of parameters, repetition, measuring, and discussion. Other means, gameplay aside, that the DSWians used to investigate DS2 included analysis of the files that make up DS2's data architecture. These files yielded how DS2 functioned on the level of software, but were hard to decipher and render usable on the DSW.

While item statistics, for example, could be discovered via the approach of playing and recording and the functioning of a spell tested, DSW knowledge practices relating to DS2's storyline and lore were purely interpretative in character. To explore DS2's narrative dimension, the DSWians commonly employed a triangulation approach where multiple sources were drawn upon and interrelated. These sources were commonly dialogue from the game, item descriptions, interviews with DS2's developers, in-game events and visuals, and the DSWians' DS1 knowledge base. The approach of triangulation was widely used in the debates regarding the relationship between the locations and NPCs of DS1 and DS2 respectively — one of the bigger points of contention regarding the lore and story aspects of DS2 that emerged during the study. For example, Kamishiro posted the following on the DSW's lore discussion message board:

Also, the pieces of the Dark Set descriptions state: 'Old foreign legends describe them as poor souls who chased the lost art of lifedrain,' meaning that the Darkwraiths [an enemy and player faction in DS1] of legend are foreign to Drangleic? Ergo Lordran is foreign? (Kamishiro, March 2014).

Here, Kamishiro drew on item descriptions from DS2 and knowledge of DS1 to argue that Drangleic (the location of DS2) and the Lordran (the location of DS1) were separate places.

\subsubsection{The warranting of knowledge}

The DSWians' venture of exploring and documenting DS2 was regulated by several practices of knowledge warranting. These practices were of two principal kinds, and pertained to the questions of what constituted a verified knowledge claim and how knowledge should be conveyed in written form on the wiki, that is, selection and appraisal as tied to the articlework process.

A knowledge claim on the DSW was warranted either when sourced properly or, in the case of gameplay elements, when a DSWian successfully recreated previously documented 
results and communicated this to the community. The following exchange in the talk space of the NPC Merchant Hag Melentia-article is indicative of how the latter procedure was usually carried out (March 2014). There, an AWC claimed: "When killed, [Melentia] drops a Silver Covetous Ring +1 [an item which raises the item discovery statistic]." A day later, another AWC submitted "Confirmed, [Melentia] drops a ring that adds item discovery when killed." "Confirmed" was the colloquial term used on the wiki to communicate that a claim had been verified. In terms of sources, consensus on the DSW was that which appeared in-game could be considered to be - in the words of Kamishiro (April 2014) — "evidence." Specifically, such sources included item descriptions, character dialogue, in-game movie clips, and gameplay mechanics. Statements by DS2's developers and DS2's official strategy guide were also generally considered to be trustworthy sources. In situations when authoritative sources supported different interpretations or conclusions, the evaluation of sources however became complex:

Which [type of source] should take priority in the case of contradictions is hard to say, however, and how to treat things that are stated by developers before the game's release is also difficult (Kamishiro, April 2014).

As illustrated here by Kamishiro, and articulated many times over in the intense debates on the nature of the relationship between DS1 and DS2 taking place during the entire length of the study, common practice on the DSW was to determine the evidentiary value of different source materials in relation to the situation at hand. Claims about DS2's narrative aspects were likewise only seen as warranted if they were referenced according to the same standards as other in-game phenomena, despite the fact that all relevant sources of lore and storyline were fragmentary and ambiguous. In a discussion of the horizons of possible knowledge regarding DS2's lore, an AWC recognized the scant available source material and wrote "we as a community of players should be careful not to interchange our beliefs [regarding DS2's narrative aspects] for evidence" (AWC, April 2014). This sentiment was echoed by, among others, Jimopup (March 2014) and Kamishiro (August 2014) in similar discussions.

The warranting of knowledge on the DSW also occurred in the process of article work, when it was decided what, among all that was known, that would be selected for presentation in the authoritative article space. These instances of appraisal and evaluation were often carried out in the context of conflict, where different priorities contended with each other. Here, two examples are of note: the primacy of site-wide structure on the DSW, and the use of the strategy guide in DSW knowledge practices. The impact of structure on the DSWians' selections of what knowledge to present in the wiki's articles was at most visible in the context of new discoveries. In May, Jimopup posted the following on DSW's message board for discussion of internal matters:

I've been digging through the Dark Souls archive [a data dump from the analysis of DS1 game datafiles] and found several hidden values for weapons. Things like stamina damage and Auxiliary defense. The weapon template doesn't support these values (Jimopup, May 2014).

Jimopup expressed concern that the additional findings regarding how weapons function in DS1 wouldn't fit in the "weapon template," that is, the primary tool used to structure the presentation of statistics on the DSW's weapon article pages. Different solutions of how to integrate the new knowledge into the article structure were discussed by Jimopup, Kamishiro, and Qing, including creating new icons, modifying the template, and presenting the hidden values for all the game's weapons in a separate article. The ultimate result of the discussion was that the discoveries relating to DS1's weapon modifiers was left out of the DSW's articles altogether. This pattern, where the DSWians chose not to include newly gained 
knowledge in the article space due to problems of presentation, appeared also in other investigations. For example: the relationship between spell durations and the player character's intelligence statistic in DS2, discovered by Tokugawa and Lenodi after discussion and testing in the DSW's chat channel, was not mentioned on the DSW article pages (June 2014).

Knowledge on the DSW was also warranted by the use of sources during the articlewriting process. An especially interesting case is the application DS2's official strategy guide, published by FuturePress, in the article work of the DSWians. The strategy guide and its use show how the warranting of knowledge on the DSW was influenced by different modes of knowing. The strategy guide became accessible to the DSWians sometime after DS2's release, and it quickly became one of the most referenced and authoritative sources on the wiki. The release of the guide led to the revision of much documentation already in place on the DSW, notably the naming of NPCs, including enemies. Before the DSWians started referencing the strategy guide, the naming of NPCs and enemies were largely based on fantasy tropes, including mythology and the narrative universe of DS1. The article dedicated to the Ogre provides an interesting example. The Ogre is one of the first enemies the player encounters in DS2; it is a large, hulking beast with a single centrally placed eye. The notable similarities between DS2's rendition of ogres and the mythological Cyclops led to that the earliest incarnations of the ogre article being given that name. In the talk field of the article in question, the following posts were found:

$A W C$ 1: These are actually Ogres, according to the [strategy] guide. $A W C 2$ : But Ogres have two eyes, these guys have one. Take a good look when you fight one next.

Xao-Xao: [Ogre] is the name used in the official guide. Unless From[Software] reveal a different name, we should stick with it.

Xao-Xao's way of reasoning represents the praxis of how similar questions of naming (enemies, special attacks, bosses, items, NPCs) were dealt with on the DSW after the release of the strategy guide. In terms of knowledge warranting, the strategy guide was privileged over mythology, fantasy and videogame tropes, and other spheres of knowledge. There were only faint competing viewpoints on the DSW, and there was a significant community consensus that communications from FromSoftware or other commercial actors affiliated with DS2-like FuturePress's strategy guide—should be seen as true and canon.

\subsection{The knowledge culture of the DSW}

The DSW's knowledge culture can be summarized by looking at five key themes that emerged from the analysis.

Boundaries. The DSW knowledge culture was externally bounded by the limits of the site and stood explicitly independent. The work of getting-to-know about DS2 was not shared with other wikis or communities, and the relationship to these were instrumental and of low intensity.

Knowledge aims and strategy. At the center of the DSW knowledge culture lay the Dark Souls games, DS2 in particular during the studied timeframe. The principal aim of the DSW enterprise was to create and maintain a DS2 documentary resource that satisfactorily met the standards and specifications established by the DSWians themselves. This work rested on the production and documentation of knowledge claims concerning the appearance and functioning of DS2. The DSW knowledge culture concerned itself primarily with positive knowledge derived from verified observations and had little room for theory-building or personal reflections. This stance informed to a significant degree the dominant empirical 
strategies on the wiki: the DSWians got-to-know DS2 via gameplay and from consulting sources outside of the game world; statements about in-game phenomena and the rules determining their interactions were warranted either via testing and corresponding observations across multiple copies of DS2, or by the authority of the sources - the game's strategy guide or statements by the game's developer FromSoftware mainly. Taken together, the knowledge-building efforts of the DSWians largely consisted of documenting information provided by DS2 or other sources on the DSW. Investigations were also conducted however, and processes of selection and appraisal were carried out in both scenarios.

Formation of the wiki. The dominant view of knowledge as positive affected the formation of the DSW as a documentary resource in the sense that only information derived from certain observations qualified to be presented on what by the DSWians considered to be the 'wiki proper' - the article pages. There was some degree of calculation and abstraction, but such operations were difficult to hold up to the DSW's knowledge standards due to the limited access to relevant sources. DS2 typically presented some of the relevant variables of an interaction to the player, but seldom all of them. The same problem applied to cumulative knowledge building on the DSW. It was often not possible to draw conclusions based on the combination of older observations and new ones, because it proved difficult to ascertain the relationship between the two. Furthermore, fanart, fanfic, and more systematic statements regarding DS2's narrative universe were for example only allowed in non-articles spaces, like the forums or personal blogs. This also applied to cases where the player base was knowledgeable, in minute detail, of the story of the Dark Souls games, lore, items, events, item descriptions, developer interviews and so on, and were able to draw on these insights to make interpretations that had the capacity to be an acceptable intersubjective result until proven invalid. However, as long as no authoritative sources or direct observations existed, this kind of reasoning was however given little credence and was often dismissed as 'speculation.'

The role of infrastructure. In the course of this study, DS2 was simultaneously the DSW's primary object of knowledge and most important empirical source. Analogically, the MediaWiki infrastructure was both the DSWians' primary documentary repository and a key tool in DSW knowledge practices. On the wiki, DS2 as an empirical source was often conceptualized akin to a landscape to advance through and explore, which was precisely how the game via gameplay and graphical representation appeared to a player. As knowledge subjects, the DSWians here acted as ecologists who moved among the environments and their objects and inhabitants with the aim of figuring out general patterns and interactions as well as individual qualities. The structures of the DSW - established during the community's documentary work relating to DS1 - affected DS2-related knowledge practices in several ways. It provided the analytical activities with a focus and a method of selection by making clear what categories of documentation that needed to be produced. The DSW also facilitated the challenge of transcribing the elements of a three-dimensional videogame to a format suitable for a wiki by showcasing the practices of article work on the site. Knorr-Cetina (1999) attributes the power of the laboratory in the sciences to their capacity to produce differences, for example between the objects as they appear in everyday life and in a postanalysis line chart. The role of the wiki in DSW knowledge production seems to be the inverse: the wiki catalogued DS2 by instituting similarities in the form of tags, categories, tables, established ways of analysis and description on the more changeable, less structured and interconnected environment that is the DS2 game world.

Stages of work. The study of the DSW shows that the apt metaphor for describing the creation of a videogame wiki is not as 'a singular communal process,' but rather as the less teleological 'groups of activities set in stages.' Practices of knowledge production on the DSW was characterized by a dynamic of directed and undirected efforts, only punctuated by 
discussions and decisions on policy and praxis that changed the direction of further activity and the appearance of the wiki. Activities like the asking of questions and the use of methods and sources moreover changed during the timeframe studied, and did not maintain the same character or focus. Similarly, to understand the evolution of the wiki as a documentary resource in different levels of completion may prove to be too imprecise, as it too strongly emphasizes continuity. In the early times after the release of DS2 the DSW comprehended a great span of varying investments and knowledge practices, which resulted in the presence of a broad spread of documentation and cultural expressions on the wiki. This variability of expressions and statements diminished as time went on, due to more comprehensive regulatory efforts, and not because a higher degree of completion by necessity implies any increased homogeneity of documentation.

\section{Discussion}

The study of the DSW shows several results that accord with observations made by earlier research. The findings support that interactions and competencies relating to information are of considerable importance and explanatory potential in the area of videogaming (Adams, 2009; Harviainen and Savolainen, 2014; Martin and Steinkuehler, 2010; Steinkuehler, 2007). This includes the analytic, synthetic, and reflective capabilities observed by Barr (2014) and Steinkuehler and Duncan (2008) in their studies of knowledge production in game-related social media resources. Knowledge practices aside, a multiplicity of related practices also took place on the DSW, including narrative practices with connections to identity formation (Albrechtslund, 2010), collaborative learning (Barr, 2014), and writing (Hunter, 2011). In accordance with the findings of Barr (2014) and Golub (2010), the primary drivers of engagement showcased by the DSWians were the enjoyment of playing DS2 and the satisfaction of participating in the knowledge practices of the wiki.

The results of the present paper also raise many interesting points in context with the findings of previous inquiries of knowledge production in videogame and fan communities. On a general level, the DSW study confirms the principal patterns observed by, among others, Steinkuehler (2007; 2008; 2010), Bullard (2013), and Mittell (2009; 2013): knowledge production on the DSW was carried out in a proficient and disciplined manner in accordance with internally set priorities and standards. However, there are also observable differences. Authenticity and credibility on the DSW were constructed via a concise and factoriented approach to article work, where statements were mandatorily sourced. The incorporation of playfulness as a strategic measure in this sense, as observed by Bullard (2013) in a study of a video-driven WoW documentary resource, was in fact deliberately counter-acted by the DSWians. Comparisons with the results of earlier research further makes it clear that resources of documentation in the area of videogames can differ significantly in terms of content, ways of working, and modes of making priorities. Taken together, these similarities and discrepancies raise interesting questions regarding the variability of the practices of knowledge-production sites across the spectrum of the Internet, and the structural factors that affect them. Previous research has discussed this topic to a limited extent. Mittell $(2009 ; 2013)$ argues that Wikipedia's guidelines and hierarchies have become the hegemonic modes of writing and making priorities in the domain of fan wikis, and attributes the emergence of certain shared orders of work to the functionalities of the MediaWiki platform. Steinkuehler and co-authors $(2007 ; 2008 ; 2010)$ identify information and science-literacy practices in online roleplaying games, which may be interpreted as indicative of how interactions of information occur in other videogaming contexts as well.

While acknowledging that important aspects of knowledge building in the videogame domain are shared among sites and communities, it is empirically shown here in what way game wikis - and by extension other types of web knowledge resources - to a significant 
degree can be considered to be bounded and particular knowledge cultures. Table 4 presents four major, mutually shaping, factors that impacted the knowledge practices of the wiki during the study of the DSW.

[Insert Table 4 here]

Although these factors are structural in the sense that they are present in the majority of videogame wikis, they were seen to impact the knowledge building on the DSW in a specific way. During the course of the study it became apparent that DS2-focused knowledge practices on the DSW were to a great extent affected by the content structures and practices established during the previous work of documenting and investigating DS1. Similarly, and as shown clearly in the analysis above, the principles and priorities that determined how knowledge practices were carried out were exclusively negotiated by the DSWians. DS2 was a challenging object of inquiry due to the scarcity of information it provided to the DSWians. It is plausible that the positive view of knowledge and lack of theory-crafting relating to gameplay mechanics on the DSW are concessions to the difficulties of obtaining data and testing hypotheses relating to DS2. This interpretation of the relationship between the nature of DS2 as an empirical object under investigation and the knowledge practices of the DSWians is strengthened by inverse examples in previous studies, where players of information-intensive videogames show an inclination towards theory and more advanced analyses (see e.g., Steinkuehler and Duncan, 2008; Warmelink, 2013). Knowledge practices on the DSW were furthermore impacted by 'canonical' knowledge made available by the DS2's developer and publisher. If representatives from these companies had acted differently, for example, said different things in interviews or had not released a strategy guide, the DSW and the characteristics of the knowledge practices taking place there would have been different.

The specific qualities of DSW knowledge-building practices furthermore tie into several strands of arguments in the related literature. Firstly, this study expands the conclusions of previous research studies by putting forward bounded and particular knowledge practices and knowledge cultures as factors influencing the content and structure of community-curated documentary resources (Barr, 2014; Bullard, 2013; Mittell, 2009, 2013; Steinkuehler and Duncan, 2008; Toton, 2008). Secondly, it connects to Wirman's (2007) questioning of the applicability of the notion of productive fandom (cf. Jenkins, 2006, 2013) in the videogaming domain. On the basis of an analysis of the many forms of productivity that players engage in, Wirman concludes that game cultures hold "new forms of productive activities that do not have counterparts among the fan activities of traditional media" (Wirman, 2007, p. 383). Wirman's argument, in conjunction with the findings of this paper, strongly indicates that parallels between the fan and videogame domains should be drawn with caution and that owing to the many types of videogames available and the many ways of playing them - there is reason to further explore the specificities of videogame knowledge cultures in future research on the topic. Thirdly and lastly, it relates to the discussion of to what extent the phenomena of Wikipedia and Wikipedia research are relevant in the study of fan and videogame wikis (see Hunter, 2011; Mittell, 2009, 2013). There is a general relevance of Wikipedia in the context under study here: Wikipedia has had an immense impact on presentday online information activities, and Wikipedia and many fan and videogame wikis use the same MediaWiki platform, although in different configurations. The shared infrastructure results in further similarities, such as the wikis' functioning as sites of communal memory retention (Pentzold, 2009) and multiple orders of knowing (Haider and Sundin, 2010; Magnus, 2009). It is reasonable to assume that the DSWians use Wikipedia and are somewhat familiar with how the site operates. During the entirely of the study however, no 
mention of or reference to Wikipedia was made. Similarities aside, there are on the other hand differences that substantially affect the usefulness of Wikipedia as a comparative example and the results of Wikipedia research in the study of videogame and fan wikis. The study of the DSW highlights Wikipedia's explicitly encyclopedic ideals and scope, along with its testimonial epistemology (Fallis, 2006; see also Wray, 2009), which limits its knowledge practices to what has already been made known, as key points of divergence. Wikipedia and videogame wikis are additionally oriented towards drastically different empirical objects of study, and as a result they host ranges of knowledge practices - for example relating to making inquiries, finding sources, choosing methods, and warranting statements - that are to a large extent dissimilar.

The results of this paper also add to the discussion of how to understand the relationship between videogames and their social media ecosystem. The principal dividing line here runs between those that construe game-related web resources as important yet separate (e.g., Boellstorff, 2008; Hamilton et al., 2014; Steinkuehler, 2007) and those that consider them as different components of a networked play space (e.g., Golub, 2010; Pearce, 2009). The results of this paper provide arguments for the latter interpretation by showing how gameplay and knowledge-building practices taking place on the DSW are highly interlinked. Gameplay emerges as a key aspect of knowledge practices; it is the DSWians' main method of investigation and warranting, and gameplay progress is seen to be connected to the organization of inquiries and the different stages of work on the wiki. The study suggests that, for the DSWians, the division between playing DS2 for leisure and participating in DSW knowledge practices was dynamic. In some scenarios, the DSWians interactions with DS2 were strictly aimed at supporting knowledge production on the wiki. In other cases, the DSWians described their gameplay and documenting activities, for instance, without making a distinction between the two. The serious-leisure perspective, put forward by Bullard (2013) as a framework to study information activities in a videogaming context, thus seems to satisfactorily characterize the nature of DSW knowledge culture as well. The activities of the DSWians are intrinsically motivated, and they showcase specialized knowledge and disciplined efforts. However, the study also indicates that the users who participate in the construction of online videogame documentary resources have different interests, motivations, and preferred ways of working - and that analyses seeking to characterize these activities should reflect their variety.

\subsection{Conclusions}

Reporting on a three-month ethnographic study of the Dark Souls Wiki ('the DSW'), the main contribution of this paper is that it puts into focus how the sociocultural underpinnings of knowledge-building ventures in the videogame domain interact with the emergence of collaborative online videogame resources of documentation. The study is strongly motivated by the current state of research: despite a tangible interest in exploring videogames and videogaming from the viewpoint of information and knowledge, few previous inquiries exists on how knowledge is produced, negotiated, and documented in videogame-related social media. The present paper analyzes and describes how the content and structure of wikis and other videogame repositories of documentation are the product of historically situated knowledge cultures. These cultures consist of an amalgamation of knowledge aims, practices, principles, and materialities that determine the character and direction of their activities. In the study of the DSW, the four major (interrelated) factors that influenced knowledge practices on the wiki were identified: $i$. the structures and practices established by the community's earlier wiki efforts; ii. the principles and priorities that informed wiki knowledge-practices; iii. the characteristics of DS2, the videogame in focus of the site's knowledge-building work; iv. the extent and types of relevant documentation provided by 
videogame industry, the videogaming press included. The results of the study add to videogame-oriented LIS research by showing the basic workings and components of communal knowledge production, and the intimate connection between such enterprises and their local configurations of knowledge cultures and infrastructures. This implies that research should relate specific instances of videogame documentation and knowledge practices to broader phenomena - e.g., Wikipedia, encyclopedic ideals, the knowledge practices of other online communities - only cautiously until these relationships and their transferability are explored further.

Future studies in the vein of the present paper should focus on exploring the mutual shaping of knowledge practices and the commonly used MediaWiki infrastructure, which additionally would benefit the understanding of Wikipedia by providing a case for comparison. Videogame wikis have periods of activity and inactivity that often are tied to the release schedule of videogames and videogame sequels and expansions. Academic attention should be directed towards this cyclical pattern of wiki knowledge production in order to gain insight into the sustainability of videogame wikis as documentary resources, and discern what impact the different phases of have on the formation and activities of the sites' knowledge cultures. The final recommendation for further study is to comparatively study the sociocultural fundaments of knowledge-producing enterprises related to different videogame communities and taking place on different types of sites (wikis, forums, Reddit). Such research would provide important insights into how knowledge cultures in the gaming domain relate to and are impacted by their varying infrastructures and principal empirical contexts - the videogame.

[1] The term 'sociocultural' is throughout this text used as a prefix to the venture of knowledge production with the intent to communicate that knowledge and the different activities and processes associated with it, are understood to be socially and culturally configured and grounded in human practice. The sociocultural perspective as it is employed here also puts emphasis on the historical and material situatedness of knowledge production, although the latter aspect is to a lesser extent in focus of the study reported in this paper (see the limitations section). The understanding of knowledge in the present inquiry thus places it in the tradition of research advanced by Latour (1979) and Knorr-Cetina (1999), rather than in relation to the sociocultural analysis of learning, teaching, and the functioning of the mind spearheaded by e.g., Lev Vygotsky and James Wertsch.

[2] If deemed necessary for the sake of clarity, spelling and grammatical errors present in the quotes have been corrected.

[3] A smaller set of data was collected outside of the three-month window of the study for complementary purposes.

[4] The names of the DSWians have been anonymized.

[5] Like Wikipedia, the majority of the DSW's functions were available to non-registered users. On the DSW, these users were collectively referred to as "AWCs"-anonymous wiki contributors. This paper employs the same naming custom.

\section{References}

Adams, S. (2005), "Information behavior and the formation and maintenance of peer cultures in massive multiplayer online role-playing games: a case study of City of Heroes", in Proceedings of the 2005 DiGRA International Conference, available at: http://www.digra.org/wp-content/uploads/digital-library/06278.15067.pdf (accessed 24 November 2016).

Adams, S. (2009), "What games have to offer: information behavior and meaning-making 
in virtual play spaces”, Library Trends, Vol. 57 No. 4, pp. 676-693.

Albrechtslund, M. (2010), "Gamers telling stories: understanding narrative practices in an online community, Convergence: The International Journal of Research into New Media Technologies, Vol. 16 No. 1, pp. 112-124.

Barr, M. (2014), "Learning through collaboration: video game wikis", International Journal of Social Media and Interactive Learning Environments, Vol. 2 No. 2, pp. 119-133.

Becher, T. (1989), Academic Tribes and Territories: Intellectual Enquiry and the Cultures of Disciplines, Society for Research into Higher Education, Milton Keynes.

Bell, D. (1973), The Coming of Post-Industrial Society: A Venture in Social Forecasting, Basic Books, New York.

Boellstorff, T. (2008), Coming of Age in Second Life: An Anthropologist Explores the Virtually Human, Princeton University Press, Princeton.

Brown, J.S. and Duguid, P. (1996), "The social life of documents", First Monday, Vol. 1 No. 1, available at: http://firstmonday.org/ojs/index.php/fm/article/view/466/387 (accessed 24 November 2016).

Buckland, M. K. (1991), Information and Information Systems: New Directions in Information Management, Greenwood, New York.

Bullard, J. (2013), "Playfully serious information for serious play: the integration of community values in an information resource", in Schamber, L. (Ed.), iConference 2013 Proceedings, iSchools, pp. 389-397.

Charmaz, K. (1983), "The grounded theory method: an explication and interpretation", in Emerson, R. (Ed.), Contemporary Field Research: A Collection of Readings, Waveland Press, Prospect Heights, pp. 109-126.

Chen, M. (2012), Leet Noobs: The Life and Death of an Expert Player Group in World of Warcraft, Peter Lang, New York.

Corbin, J. M. and Strauss, A. (1990), "Grounded theory research: procedures, canons, and evaluative criteria", Qualitative Sociology, Vol. 13 No. 1, pp. 3-21.

Cunningham, W. and Leuf, B. (2002), "What is Wiki", available at http://www.wiki.org/wiki.cgi?WhatIsWiki (accessed 24 November 2016).

Davies, E. (2008), "The script as mediating artifact in professional theater production", Archival Science, Vol. 8, No. 3, pp. 181-198.

Fallis, D. (2006), "Social epistemology and information science", Annual Review of Information Science and Technology, Vol. 40 No. 1, pp. 475-519.

Fallis, D. (2008), "Toward an epistemology of Wikipedia", Journal of the American Society for Information Science and Technology, Vol. 59 No. 10, pp. 1662-1674.

Frohmann, B. (2004), Deflating Information: From Science Studies to Documentation, University of Toronto Press, Toronto.

Gatson, S. N. (2011), "The methods, ethics, and politics of representation in online ethnography", in Denzin, N. K. and Lincoln, Y. S. (Eds.), Handbook of Qualitative Research, SAGE Publications, Thousand Oaks, pp. 513-527.

Geertz, C. (1973), The Interpretation of Cultures: Selected Essays, Basic Books, New York.

Geiger, R.S. and Ribes, D. (2011), "Trace ethnography: following coordination through documentary practices", in Sprague, R.H. Jr (Ed.), Proceedings of the 44th Hawaii International Conference on System Sciences, IEEE Computer Society, Los Alamitos.

Glaser, B. and Strauss, A. (1967), The Discovery of Grounded Theory: Strategies for Qualitative Research, Aldine de Gruyter, New York.

Golub, A. (2010), "Being in the World (of Warcraft): raiding, realism, and knowledge production in a massively multiplayer online game, Anthropological Quarterly, Vol. 83 No. 1, pp. 17-46.

Haider, J. and Sundin, O. (2010), "Beyond the legacy of the enlightenment? Online 
encyclopaedias as digital heterotopias", First Monday, Vol. 15 No 1, available at: http://firstmonday.org/article/view/2744/2428 (accessed 24 November 2016).

Hamilton, W. A., Garretson, O., and Kerne, A. (2014), "Streaming on Twitch: fostering participatory communities of play within live mixed media, in CHI Conference on Human Factors in Computing Systems Toronto, ON, Canada-April 26 - May 01, 2014, ACM, New York, pp. 1315-1324.

Harrison, R. (2009), "Excavating Second Life: cyber-archaeologies, heritage and virtual communities", Journal of Material Culture, Vol. 14 No. 1, pp. 75-106.

Hartel, J. (2010), "Managing documents at home for serious leisure: a case study of the hobby of gourmet cooking", Journal of Documentation, Vol. 66 No. 6, pp. 847-874.

Harviainen, J.T., Gough, R.D. and Sköld, O. (2012), "Information phenomena in gamerelated social media", in Widén, G. and Holmberg, K. (Eds), Social Information Research, Emerald, Bingley, pp. 149-171.

Harviainen, J. T. and Hamari, J. (2015), "Seek, share, or withhold: information trading in MMORPGs", Journal of Documentation, Vol. 71 No. 6, pp. 1119-1134.

Harviainen, J. T. and Savolainen, R. (2014), "Information as capability for action and capital in synthetic worlds", Information Research, Vol. 19 No. 2, available at: http://www.informationr.net/ir/19-4/isic/isic12.html\#.WDbQU3diSHo (accessed 24 November 2016).

Harviainen, J. T. and Vesa, M. (2016), "Massively Multiplayer Online Games as Information System: Implications for Organizational Learning, in Kaneda, T., Kanegae, H., Toyoda, Y., and Rizzi, P. (Eds.), Simulation and Gaming in the Network Society, Springer Singapore, Singapore, pp 199-214.

Hine, C. (2000), Virtual Ethnography, SAGE Publications, London.

Hunter, R. (2011), “Erasing 'property lines': a collaborative notion of authorship and textual ownership on a fan wiki", Computers and Composition, Vol. 28 No. 1, pp. 4056.

Jemielniak, D. (2014), Common Knowledge? An Ethnography of Wikipedia, Stanford University Press, Stanford.

Jenkins, H. (2006), Fans, Bloggers, and Gamers: Exploring Participatory Culture, New York University Press, New York.

Jenkins, H. (2013), “Textual Poachers: Television Fans and Participatory Culture”, Routledge, New York.

Karlova, N. and Lee, J. H. (2012), "Playing with information: information work in online gaming environments", in iConference 2012 Proceedings, ACM, New York, pp. 441443.

Knorr-Cetina, K. (1999), Epistemic Cultures: How the Sciences Make Knowledge, Harvard University Press, Cambridge.

Latour, B. and Woolgar, S. (1979), Laboratory Life: The Social Construction of Scientific Facts, SAGE Publications, Beverly Hills.

Law, J. and Lynch, M. (1988)," Lists, field guides, and the descriptive organization of seeing: Birdwatching as an exemplary observational activity", Human Studies, Vol. 11 No. 2/3, pp. 271-303.

Magnus, P. D. (2009), "On trusting Wikipedia", Episteme, Vol. 6 No. 1, pp. 74-90.

Malaby, T. M. (2007), "Beyond play: a new approach to games", Games and Culture, Vol. 2 No. 2, pp. 95-113.

Marcus, G. E. (1995), "Ethnography in/of the world system: the emergence of multi-sited ethnography”, Annual Review of Anthropology, Vol. 24, No. 1, pp. 95-117.

Markham, A. (2013), "Fieldwork in social media: what would Malinowski do?", Qualitative Communication Research, Vol. 2, No. 4, pp. 434-446. 
Martin, C. and Steinkuehler, C. (2010), "Collective information literacy in massively multiplayer online games", E-Learning and Digital Media, Vol. 7 No. 4, pp. 355-365.

McKenzie, P. J. and Davies, E. (2010), "Documentary tools in everyday life: the wedding planner", Journal of Documentation, Vol. 66 No. 6, pp. 788-806.

Mittell, J. (2009), "Sites of participation: wiki fandom and the case of Lostpedia", Transformative Works and Cultures, Vol. 3, available at: http://journal.transformativeworks.org/index.php/twc/article/view/118/117 (accessed 24 November 2016).

Mittell, J. (2013), "Wikis and participatory fandom", in Delwiche, A. and Henderson, J. J. (Eds.), The Participatory Cultures Handbook, Routledge, New York, pp. 35-42.

Nardi, B. A. (2010), My Life as a Night Elf Priest: An Anthropological Account of World of Warcraft, University of Michigan Press, Ann Arbor.

Newman, J. (2011), “(Not) playing games: player-produced walkthroughs as archival documents of digital gameplay, The International Journal of Digital Curation, Vol. 6 No. 2, pp. 109-127.

Nissenbaum, H. F. (2010), Privacy in Context: Technology, Policy, and the Integrity of Social Life, Stanford Law Books, Stanford.

Pearce, C. (2009), Communities of Play: Emergent Cultures in Multiplayer Games and Virtual Worlds, MIT Press, Cambridge.

Pentzold, C. (2009), "Fixing the floating gap: the online encyclopaedia Wikipedia as a global memory place", Memory Studies, Vol 2 No. 2, pp. 255-272.

Purchese, R. (2015), “Dark Souls series sales surpass 8.5 million”, Eurogamer, available at http://www.eurogamer.net/articles/2015-07-01-dark-souls-series-sales-surpass-8-5million (accessed 24 November 2016).

Reagle, J. M. (2010), Good Faith Collaboration: The Culture of Wikipedia, MIT Press, Cambridge.

Schatzki, T. R. (1996), Social Practices: A Wittgensteinian Approach to Human Activity and the Social, Cambridge University Press, Cambridge.

Schuurman, N. (2008), "Database ethnographies using social science methodologies to enhance data analysis and interpretation", Geography Compass, Vol. 2 No. 5, pp. $1529-1548$.

Shankar, K. (2009), "Ambiguity and legitimate peripheral participation in the creation of scientific documents", Journal of Documentation, Vol. 65 No. 1, pp. 151-165.

Shaw, A. (2010), "What is video game culture? Cultural studies and game studies", Games and Culture, Vol. 5 No. 4, pp. 403-424.

Sköld, O., Adams, S., Harviainen, J. T., and Huvila, I. (2015), "Studying games from the viewpoint of information", In Lankoski, P. and Björk, S. (Eds.), Game Research Methods, ETC Press, Pittsburgh, pp. 57-73.

Stanton, R. (2014), "Becoming the Dark Soul”, Eurogamer, available at http://www.eurogamer.net/articles/2012-10-25-becoming-the-dark-soul (accessed 24 November 2016).

Stebbins, R. A. (1982), "Serious Leisure: A Conceptual Statement”, The Pacific Sociological Review, Vol. 25 No. 2, pp. 251-272.

Stebbins, R. A. (1997), “Casual leisure: a conceptual statement”, Leisure Studies, Vol. 16 No. 1, pp. 17-25.

Steinkuehler, C. (2007), "Massively multiplayer online gaming as a constellation of literacy practices, E-Learning and Digital Media, Vol 4 No. 3, pp. 297-318.

Steinkuehler, C., Compton-Lilly, C., and King, E. (2010), "Reading in the context of online games, in Gomez, K., Lyons, L., and Radinsky, J. (Eds.), 
Proceedings of the 9th International Conference of the Learning Sciences, International Society of the Learning Sciences, pp. 222-229.

Steinkuehler, C. and Duncan, S. (2008), "Scientific Habits of Mind in Virtual Worlds", Journal of Science Education and Technology, Vol. 17 No. 6, pp. 530-543.

Sundin, O. (2011), "Janitors of knowledge: constructing knowledge in the everyday life of Wikipedia editors", Journal of Documentation, Vol. 67 No. 5, pp. 840-862.

Taylor, T. (2006), Play Between Worlds: Exploring Online Game Culture, MIT Press, Cambridge.

Tollefsen, D. P. (2009), "Wikipedia and the epistemology of testimony", Episteme, Vol. 6 No. 1, pp. 8-24.

Toton, S. (2008), "Cataloging knowledge: gender, generative fandom, and the Battlestar wiki", Flow, Vol. 7 No. 14, available at:

http://www.flowjournal.org/2008/01/cataloging-knowledge-gender-generativefandom-and-the-battlestar-wiki/ (accessed 24 November 2016).

Trace, C. B. (2007), "Information creation and the notion of membership", Journal of Documentation, Vol. 63 No. 1, pp. 142-164.

Vesa, M. (2013), There Be Dragons! An Ethnographic Inquiry into the Strategic Practices and Process of World of Warcraft Gaming Groups, Hanken School of Economics, Helsinki.

Warmelink, H. (2013), Online Gaming and Playful Organization, Routledge, New York.

Wikia, (2017), "Community Creation Policy", available at: http://www.wikia.com/Community_Creation_Policy (accessed 19 June 2017).

Wirman, H. (2007), “'I am not a fan, I just play a lot' if power gamers aren't fans, who are?", in Proceedings of the 2007 DiGRA International Conference, available at: http://www.digra.org/wp-content/uploads/digital-library/07311.40368.pdf (accessed 24 November 2016).

Wray, B. K. (2009), "The epistemic cultures of science and Wikipedia: a comparison", Episteme, Vol. 6 No. 1, pp. 38-51. 
Table 1

Table 1. Empirical foci in the study of the DSW, drawn from Knorr-Cetina (1999) and Becher (1989).

\begin{tabular}{|l|l|}
\hline Empirical focus & Phenomena and occurrences drawn into view \\
\hline General characteristics & $\begin{array}{l}\text { The overall nature, boundaries, and aims in and of } \\
\text { the DSW knowledge-culture }\end{array}$ \\
\hline Inquiries & How inquiries are organized, and questions asked \\
\hline & Major types of inquiries and questions \\
\hline Methods \& means & $\begin{array}{l}\text { What is considered to be knowable, and what is } \\
\text { considered to be unknowable }\end{array}$ \\
\hline Sources & $\begin{array}{l}\text { Investigative methods and means of knowledge } \\
\text { production that are employed }\end{array}$ \\
\hline Warranting & Information sources that are considered usable \\
\hline
\end{tabular}

\section{Table 2}

Table 2. An overview of common knowledge practices on the DSW.

\begin{tabular}{|c|c|c|}
\hline Practice & Description & Example from the data \\
\hline Article work & $\begin{array}{l}\text { The creation, writing, and } \\
\text { editing of articles }\end{array}$ & $\begin{array}{l}\text { "Thanks for cleaning up the article of Lost Sinner's sword. } \\
\text { I'm new to wiki editing" (Ming, March 2014). }\end{array}$ \\
\hline Inquiry & $\begin{array}{l}\text { The planning, execution, and } \\
\text { reporting of inquiries aimed } \\
\text { at gaining insight into DS2 }\end{array}$ & $\begin{array}{l}\text { "This post aims to establish what rumors floating around } \\
\text { the internet and what are false" (Tomiko, April 2014). }\end{array}$ \\
\hline $\begin{array}{l}\text { Asking \& } \\
\text { answering of } \\
\text { questions }\end{array}$ & $\begin{array}{l}\text { The posing and answering of } \\
\text { questions about DS } 2 \text { or the } \\
\text { DSW to fellow DSWians }\end{array}$ & $\begin{array}{l}\text { "How do you use [the item Human effigy]? Do you have to } \\
\text { offer it to the bonfire in order to go back to human or just } \\
\text { use it as the Stone of Ephemeral Eyes?" (Haruna, March } \\
\text { 2014). }\end{array}$ \\
\hline $\begin{array}{l}\text { Lore } \\
\text { interpretation }\end{array}$ & $\begin{array}{l}\text { Theory-building and } \\
\text { interpretation with regards to } \\
\text { the lore of DS } 2\end{array}$ & $\begin{array}{l}\text { "Maybe it was a test set up by [the boss] Nashandra to find } \\
\text { someone strong enough to retrieve the Ring?" (Kotone, } \\
\text { April 2014). }\end{array}$ \\
\hline $\begin{array}{l}\text { Policy and } \\
\text { rules-work }\end{array}$ & $\begin{array}{l}\text { Establishment and } \\
\text { enforcement of policies and } \\
\text { site rules, incl. the } \\
\text { warranting of knowledge }\end{array}$ & $\begin{array}{l}\text { "Standardization is important across articles [...]" } \\
\text { (Kamishiro, March 2014). }\end{array}$ \\
\hline $\begin{array}{l}\text { File } \\
\text { management }\end{array}$ & $\begin{array}{l}\text { The uploading, description, } \\
\text { and use of files (e.g., images } \\
\text { and videos) }\end{array}$ & $\begin{array}{l}\text { "External media such as images and videos [make] the wiki } \\
\text { more interesting to look at" (Jimopup, June 2014). }\end{array}$ \\
\hline $\begin{array}{l}\text { Tool } \\
\text { management }\end{array}$ & $\begin{array}{l}\text { The creation and revision of } \\
\text { article management tools } \\
\text { like categories and templates }\end{array}$ & $\begin{array}{l}\text { "It was pretty close, however, it would have been far easier } \\
\text { (and less time-consuming) to use the DaSIIWeapon } \\
\text { template" (Furuken, March 2014). }\end{array}$ \\
\hline Organize work & The organization of tasks & $\begin{array}{l}\text { "Well, there's a ton of stuff to do, of course. One thing that } \\
\text { is very important is to make the newer articles up to } \\
\text { standard and to conform with the Manual of Style [...]" } \\
\text { (Kamishiro, March). }\end{array}$ \\
\hline
\end{tabular}

\section{Table 3}

Table 3. Commonly used methods and sources.

\begin{tabular}{|l|l|l|}
\hline Method & Typical source material & Description \\
\hline $\begin{array}{l}\text { Gather data from } \\
\text { other sites, } \\
\text { communities \& } \\
\text { sources }\end{array}$ & $\begin{array}{l}\text { Live streaming services, } \\
\text { YouTube, Reddit, DS2 } \\
\text { promotions, gaming news sites, } \\
\text { other DS2 communities, the } \\
\text { official strategy guide }\end{array}$ & $\begin{array}{l}\text { A much-used method before the release of DS2; } \\
\text { when released, the official strategy guide became } \\
\text { important for otherwise hard-to-get information }\end{array}$ \\
\hline $\begin{array}{l}\text { In-game } \\
\text { experiments }\end{array}$ & DS2 & $\begin{array}{l}\text { Often used when investigating complex cause-effect } \\
\text { relationships, e.g., to attempt to identify the } \\
\text { parameters of a gameplay mechanic }\end{array}$ \\
\hline
\end{tabular}




\begin{tabular}{|l|l|l|}
\hline $\begin{array}{l}\text { To play and to } \\
\text { document }\end{array}$ & DS2 & $\begin{array}{l}\text { Includes directed and undirected recording; often } \\
\text { used when investigating less complex phenomena, } \\
\text { e.g., stats, dialogue, locations, item descriptions, } \\
\text { simple cause-effect relationships }\end{array}$ \\
\hline Ask the DSW & Non-article spaces & $\begin{array}{l}\text { Pose questions to fellow DSWians; performed in the } \\
\text { talk, forum, user blog, and other non-article } \\
\text { locations on the DSW }\end{array}$ \\
\hline $\begin{array}{l}\text { Confirmation by } \\
\text { replication }\end{array}$ & DS2 & $\begin{array}{l}\text { The warranting of experiments, recordings, or } \\
\text { findings by attempting to replicate the results in } \\
\text { DS2 }\end{array}$ \\
\hline Triangulation & $\begin{array}{l}\text { Item descriptions, dialogue, } \\
\text { developer statements, previous } \\
\text { Dark Souls games, DS2 game- } \\
\text { world }\end{array}$ & $\begin{array}{l}\text { Interpretation of the interrelations of multiple } \\
\text { sources }\end{array}$ \\
\hline $\begin{array}{l}\text { Analysis of } \\
\text { extracted data }\end{array}$ & $\begin{array}{l}\text { Game file-architecture; text } \\
\text { dumps }\end{array}$ & The export and analysis of data from the game files \\
\hline
\end{tabular}

\section{Table 4}

Table 4. Major factors affecting knowledge practices on the DSW.

\begin{tabular}{|l|l|l|}
\hline Shaping factor & Description & Articulation in the DSW study \\
\hline $\begin{array}{l}\text { Earlier knowledge- } \\
\text { building efforts }\end{array}$ & $\begin{array}{l}\text { The structures and practices of } \\
\text { previous wiki-work }\end{array}$ & $\begin{array}{l}\text { The structures and practices of knowledge } \\
\text { production of the DS1 portion of the DSW }\end{array}$ \\
\hline $\begin{array}{l}\text { Principles and } \\
\text { priorities }\end{array}$ & $\begin{array}{l}\text { The principles and priorities that } \\
\text { informed knowledge practices } \\
\text { on the wiki }\end{array}$ & $\begin{array}{l}\text { The principles and priorities articulated in the } \\
\text { modes of inquiry, sourcing, warranting, and choice } \\
\text { of methods on the DSW }\end{array}$ \\
\hline The videogame & $\begin{array}{l}\text { The characteristics of the } \\
\text { videogame in focus of the wiki }\end{array}$ & The scarcity of information provided by DS2 \\
\hline $\begin{array}{l}\text { The videogame } \\
\text { industry }\end{array}$ & $\begin{array}{l}\text { The extent and types of } \\
\text { information provided by the } \\
\text { videogame press and DS2's } \\
\text { publisher and developer }\end{array}$ & $\begin{array}{l}\text { The interviews with DS2's developers; the official } \\
\text { strategy guide; invitation to DS2 pre-release play } \\
\text { tests }\end{array}$ \\
\hline
\end{tabular}

